\title{
Serotonergic Influence on Olfactory Learning in the Neonate Rat
}

\author{
John H. McLean, ${ }^{*}$ Andrea Darby-King,* Regina M. Sullivan, $\dagger$ and Shelley R. King*,1 \\ *Division of Basic Medical Sciences, Memorial University of Newfoundland, St. John's, Newfoundland, Canada A1B 3V6; and \\ $\dagger$ Developmental Psychobiology Laboratory, Department of Psychology, University of Oklahoma, Norman, Oklahoma 73019
}

The role of the serotonergic innervation of the olfactory bulb was examined in neonate rat pups (Sprague-Dawley) by utilizing an olfactory learning paradigm (Sullivan, McGaugh, \& Leon, 1991; Sullivan, Wilson, \& Leon, 1989). One hundred fifty nanoliters of the neurotoxin 5,7-dihydroxytryptamine $(5,7-\mathrm{dHT}, 10 \mu \mathrm{g} / \mu \mathrm{l})$ was injected into each anterior olfactory nucleus of Postnatal Day 2 (PND 2) pups in order to selectively deplete the serotonergic (5-HT) innervation of the olfactory bulb. On PND 8, control, sham-operated, or 5-HT-depleted pups were presented with stroke (unconditioned stimulus) paired with peppermint odor (conditioned stimulus) or were presented with peppermint alone. Other pups remained naive, i.e., they were not presented with either stroke or odor. The following day, the pups were placed on a mesh screen above two boxes containing either fresh bedding or bedding with peppermint odor for five 1-min trials. Control and sham-operated pups that were previously trained by the odor/stroke paradigm spent significantly more time over the peppermint odor than similarly trained 5-HTdepleted pups, pups trained using the odor only paradigm, or naive pups. Immunocytochemistry verified that the 5,7dHT injections specifically depleted the 5-HT innervation of the olfactory bulb and left the 5-HT innervation of more caudal levels of the neuraxis (e.g., piriform cortex) intact. The locomotor behavior of the pups was not affected by the 5-HT depletions. This study is the initial investigation to suggest that 5-HT innervation to the olfactory bulb is important in the acquisition or expression of olfactorybased learned behavior in the neonate rat. 1993 Academic Press, Inc.

\section{INTRODUCTION}

Serotonin (5-HT) is involved in such diverse functions and behaviors as sleep (Maeda, Fujimiya, Kitahama, Imai, \& Kimura, 1989; Vanderwolf, 1992),

\footnotetext{
1 The authors are grateful for financial support from the Medical Research Council of Canada (J.H.M.) and National Science Foundation (R.M.S.). We thank S. Nurse, S. Evans, D. Corbett, and S. L. Tucker for help running the locomotion studies. Address correspondence and reprint requests to John $\mathrm{H}$. McLean.
}

locomotion (Motles, Gomez, Briones, \& Gonzalez, 1991; Vanderwolf, 1989), mood (Syvalahti, 1987; Curzon, 1988; Burrows, McIntyre, Judd, \& Norman, 1988), and developmental differentiation (Lauder, Wallace, Krebs, Petrusz, \& McCarthy, 1982; Lauder, 1990). In addition, in combination with cholinergic axons, serotonergic input to the cortex appears to be important for certain memory/learning functions in the adult rat (Sakurai \& Wenk, 1990; Normile, Jenden, Kuhn, Wolf, \& Altman, 1990). In contrast to the numerous roles ascribed to 5-HT in other parts of the CNS, the role of 5-HT in the olfactory bulb has been quite elusive. Indeed, we have found that lack of serotonergic input to the developing olfactory bulb has very little, if any, effect on the cytoarchitecture of that structure (McLean, 1991), even though other studies have suggested such a role in the developing neocortex (Lauder, Wallace, Krebs, Petrusz, \& McCarthy, 1982; Lauder, 1990). However, the fact that 5-HT begins to proliferate in the olfactory bulb during the first week of postnatal life (McLean \& Shipley, 1987a) and richly innervates the bulb in the adult rat (McLean \& Shipley, 1987b) suggests that it has a developmental/functional role in olfaction that begins during early postnatal life. A functional role for 5-HT in the bulb is especially probable since the glomeruli, the first site of transfer of olfactory information from the nose to the CNS, is the most densely innervated serotonergic target in the bulb of the rat (McLean \& Shipley, 1987a).

Noradrenergic fibers from the locus coeruleus, another afferent source to the olfactory bulb, may provide some indication of how 5-HT functions in the bulb. Norepinephrine has recently been shown to be necessary for the acquisition of learned olfactory behavior in the neonate rat pup (Sullivan, Wilson, \& Leon, 1989; Sullivan, McGaugh, \& Leon, 1991; Sullivan \& Wilson, 1991). Early olfactory learning is of critical importance to newborn rat pups because 
pups must orient to their mother (Johanson \& Hall, 1982) and attach to the nipple (Pedersen, Williams, \& Blass, 1982) based on olfactory cues. One way pups learn an odor is by pairing the odor with tactile stimulation (Pedersen et al., 1982; Sullivan, Hofer, \& Brake, 1986; Sullivan et al., 1991) such as the mother licking the pups; a process which corresponds to classical conditioning (Sullivan \& Hall, 1988). The observation that norepinephrine is involved in the olfactory learning paradigm may be relevant to the serotonergic actions in the bulb because of the similarities between the noradrenergic and serotonergic innervation of the bulb. For example, the locus coeruleus provides neuromodulatory inputs to widespread cortical and subcortical regions (Foote, Bloom, \& Aston-Jones, 1983, for review). Similarly, the serotonergic system is also widespread in its distribution (Lidov, Grzanna, \& Molliver, 1980; Kosofsky \& Molliver, 1987) and is often neuromodulatory in its physiological activities (Mason, 1988; Waterhouse, Moises, \& Woodward, 1986). Another similarity between the two systems is that they both dramatically increase innervation to the olfactory bulb during the first postnatal week (McLean \& Shipley, 1987a, 1991) when many new olfactory cues are being learned. Thus, 5 -HT is developmentally and neuroanatomically situated to influence olfactory processes at an early site in synaptic processing just as noradrenergic fibers are. Whereas norepinephrine has an established role in conditioned olfactory learning, it may not be the only neurotransmitter involved in such function. We hypothesize that the serotonergic input to the olfactory bulb may provide an important component of olfactory learning and the present study represents the initial investigation of this potential role in the neonatal rat.

\section{METHODS}

\section{Animals}

A total of 100 Sprague-Dawley rat pups (male and female) from 9 litters was used. Time-pregnant females were housed at $22^{\circ} \mathrm{C}$ in polycarbonate cages containing hardwood chips (Charles River) in the animal care facility in the Health Sciences Centre at Memorial University. Food (Purina lab chow No. 2015) and water were available ad libitum and the room was kept on a 12-h-light and 12-h-dark cycle. The day prior to giving birth, the pregnant rats were brought to the research laboratory where temperature and light conditions were maintained at similar temperature and light cycles as the animal care facility. The day of birth was considered PND 1. Experiments were approved by the President's Committee on Animal Bioethics and Care at Memorial University which follows guidelines of the Canadian Council on Animal Care.

\section{5-HT Depletion Procedures}

On PND 2, pups were categorized under one of three conditions: (1) 5-HT depleted, (2) sham-operated, or (3) control. Depleted and sham-operated pups were given $50 \mu \mathrm{l}$ desipramine $(0.2 \mathrm{mg} / 50 \mu \mathrm{l}$, Sigma) $45 \mathrm{~min}$ prior to surgery. Control pups received no desipramine pretreatment or surgery. The pups were anesthetized on ice and held in a Narishige stereotaxic apparatus that was modified to firmly hold the head of small pups. We previously showed that serotonergic fibers from the dorsal and median raphe nuclei densely innervate the anterior olfactory nucleus (AON) by PND 1 and begin to proliferate in the olfactory bulb during the first postnatal week (McLean \& Shipley, 1987a). Therefore, in order to prevent growing or proliferating serotonergic fibers that have reached the AON from reaching the bulb, bilateral injections of a neurotoxin were made into the AON. A 26-gauge 1- $\mu 1$ Hamilton syringe was used to inject $150 \mathrm{nl}$ of 5,7dihydroxytryptamine (5,7-dHT, $10 \mu \mathrm{g} / \mu \mathrm{l}$, Sigma) in Ringer's solution containing $0.02 \%$ ascorbic acid into the anterior olfactory nucleus $(\mathrm{AP}=2.5 \mathrm{~mm}$, Lat $=0.5 \mathrm{~mm}$, Horizontal $=2.0-2.5 \mathrm{~mm})$. The vehicle (sham) or 5,7-dHT solution was injected at a rate of $50 \mathrm{nl}$ per minute at each of three depths (Horizontal: $2.5,2.25$, and $2.0 \mathrm{~mm}$ ). After injection of the total $150 \mathrm{nl}$ into each AON, the needle tip was raised slightly and kept at that site for an additional 2 min before it was slowly removed from the brain. The incision was closed with 6-0 silk suture and the pup was revived by warming under a lamp. The pup was returned to its mother when it became active and alert after surgery.

From each litter of pups, a total of 8-17 pups (average litter size of 11 pups) was used in order to include 4-6 experimental paradigms during each litter. The paradigms included odor/stroke controls, odor/stroke shams, odor/stroke depleted, odor only controls, odor only shams, odor only depleted, naive controls, naive shams, or naive depleted (see below under Odor Conditioning for further clarification). Generally, a male and female pup was used for each paradigm that was examined from each litter. Before training on PND 8, all pups were weighed to determine if surgical procedures had caused weight loss. 


\section{Odor Conditioning}

Rat pups can acquire conditioned olfactory learning after only one training session (Sullivan et al., 1991; Pedersen et al., 1982). Therefore, the protocols of the present experiment utilized a one training session paradigm for conditioned olfactory learning. On PND 8, the control, sham-operated, or 5-HTdepleted pups were either trained (odor/stroke or odor only) or left untrained (naive) providing a total of nine conditions that were examined. Further control groupings were possible (odor not paired with stroking or stroke alone) but these have been performed previously and they do not result in preference of an odor by the pups (Sullivan et al., 1989; 1991; Sullivan \& Leon, 1986; Pedersen et al. 1982; Sullivan \& Hall, 1988). Therefore, the additional control groups were considered to be redundant and not included in the present study. Odor conditioning of sham-operated and depleted pups was conducted blind while the procedures performed on control pups were not conducted blind since they could be identified by virtue of having no surgical marks on their skin.

Each pup was removed from its mother and placed on fresh bedding under a lamp $\left(30-32^{\circ} \mathrm{C}\right)$ for $10 \mathrm{~min}$ before training. This procedure allowed the pup to recover from handling and kept it comfortably warm. In another area of the lab, $375 \mathrm{ml}$ of fresh bedding was mixed with $0.25 \mathrm{ml}$ of pure peppermint extract (conditioned stimulus). For the odor/stroke paradigm, the pup was placed on the peppermintscented bedding under a lamp $\left(30^{\circ} \mathrm{C}\right)$ and stroked using a soft brush (unconditioned stimulus) vigorously every other $30 \mathrm{~s}$ for $30 \mathrm{~s}$ during the 10-min conditioning period. The stroking was strong enough to elicit activity in the pup and has been used by others to mimic maternal behavior (Pedersen et al., 1982; Sullivan et al., 1991; Weldon, Travis, \& Kennedy, 1991). For the odor only paradigm, the pup was placed on the peppermintscented odor under a lamp $\left(30^{\circ} \mathrm{C}\right)$ for the same 10 min period but received no stroking stimulus. Each pup was then returned to its mother for $23-25 \mathrm{~h}$ before odor testing. We also used another odor, vanillin, as a conditioned stimulus with similar results as using peppermint (unpublished observations).

\section{Odor Testing}

On PND 9, each pup belonging to one of the nine conditions was individually given an odor preference test. The tester was blind to the previous conditioning paradigm of the pups. A stainless steel testing box $(36 \times 20 \times 18 \mathrm{~cm})$ with a mesh bottom
$(1 \times 1 \mathrm{~cm})$ was centered over two trays $(18 \times 18$ $\mathrm{cm}$ ). The trays were $2 \mathrm{~cm}$ apart from each other, creating a neutral zone down the middle of the box. One tray contained $500 \mathrm{ml}$ of fresh bedding while the other tray contained $500 \mathrm{ml}$ of bedding scented with $0.3 \mathrm{ml}$ of peppermint extract. A fine polypropylene mesh was placed over the floor of the box to allow comfortable movement of the pups.

The trials were $1 \mathrm{~min}$ in length and began by placing the pup in the neutral zone. When the pup's head and both forepaws crossed into the control or peppermint area, a timer for that area was started. The cumulative time spent in each area during the 1-min trial was recorded. A total of five trials was performed. The pup was removed from the testing box after trial and the direction in which the pup was placed in the box for each trial was reversed. Analysis of the trials was done by using analysis of variance (ANOVA) and post hoc $t$ test with $p$ values corrected by the Bonferroni method (Bonferroni $t$ test) to compare 5-HT-depleted animals to all other animals. The data were plotted using Sigmaplot (Jandel Sci.)

\section{Locomotor Testing}

Between PND 10 and PND 14, the pups were given a 3-min open-field test for locomotor activity within a $21 \times 21 \mathrm{~cm}$ area. The floor was divided into nine squares by computer imaging. Locomotor activity in the nine squares was monitored (Corbett, Evans, Thomas, Wang, \& Jonas, 1990) by a videocamera and a microcomputer-based image tracking system (HSV Systems, Kingston, UK). ANOVA and the post hoc Bonferroni $t$ test was used to compare the activity (number of squares entered in $3 \mathrm{~min}$ ) of 5,7-dHT-injected pups with sham-operated and unoperated controls.

\section{Immunocytochemistry}

After all testing had been performed, randomly selected pups (PND 13-15) from each of three surgical procedures (controls, shams, 5,7-dHT depletions) were given an overdose of sodium pentobarbital and perfused transcardially with a solution of ice-cold $4 \%$ paraformaldehyde and $0.1 \%$ glutaraldehyde in $0.1 M$ phosphate buffer for $30 \mathrm{~min}$ (10 $\mathrm{ml} / \mathrm{minute}$ ). A total of 11 control, 10 sham, and 20 5,7-dHT-injected pups were perfused for immunocytochemical analysis. The brains were removed from the skull, postfixed in the fixative solution for $1 \mathrm{~h}$ on ice, and then put into $20 \%$ sucrose in phosphate buffer overnight at $4^{\circ} \mathrm{C}$. Transverse sections through the olfactory bulb and caudal to the level 
of the nucleus accumbens were cut at $30 \mu \mathrm{m}$ using a cryostat and placed directly onto chrom alumgelatin-subbed slides. The sections were incubated at $4^{\circ} \mathrm{C}$ for $24-48 \mathrm{~h}$ with antibodies to 5-HT (INCSTAR) and dopamine- $\beta$-hydroxylase (Eugene Tech.) to detect serotonergic or noradrenergic axons, respectively. An antibody to tyrosine hydroxylase (Eugene Tech.) was used to detect intrinsic dopaminergic cells of the olfactory bulb. Dilutions of the primary antibodies and secondary visualization methods have been described previously (McLean, Shipley, Nickell, Aston-Jones, \& Reyher, 1989; McLean \& Shipley, 1987b, 1988).

Quantification of the serotonergic and noradrenergic fibers was made with the aid of camera lucida drawings and a Bioquant (R\&M Biometrics) image analysis system. Because the immunocytochemistry was not optimal in some animals, only those brains that were optimally stained were used for quantitative analysis. In order to quantitate the fiber densities, immunocytochemically identified serotonergic or noradrenergic axons were identified in selected regions of the olfactory bulb (glomerular layer, external plexiform layer, and inframitral cell region) or anterior piriform cortex (layer 1, dorsomedial to the lateral olfactory tract) and drawn under darkfield microscopy using a camera lucida ( $\times 20$ objective). Layer 1 of the anterior piriform cortex was selected for analysis because it was caudal to the 5,7-dHT injections and could be consistently located for analysis. For each region that was examined, one field of approximately 100,000$300,000 \mu \mathrm{m}^{2}$ per animal was drawn. The line drawings were then input to the image analysis system in order to obtain fiber densities expressed as $\mu \mathrm{m} / 100 \mu \mathrm{m}^{2}$. ANOVA and the post hoc Bonferroni $t$ test were used to assess differences in axon densities between experimental animals, shams, and controls.

\section{RESULTS}

Overall, the experiments showed that bilateral depletion of the serotonergic input to the olfactory bulbs of neonate rat pups resulted in their inability to acquire or express conditioned olfactory learning.

\section{Conditioned Olfactory Testing}

The following observations include both sexes since both displayed similar responses to the odor tests. Control pups and sham-operated pups that were given one training session of odor/stroke showed a high degree of preference for the pep-

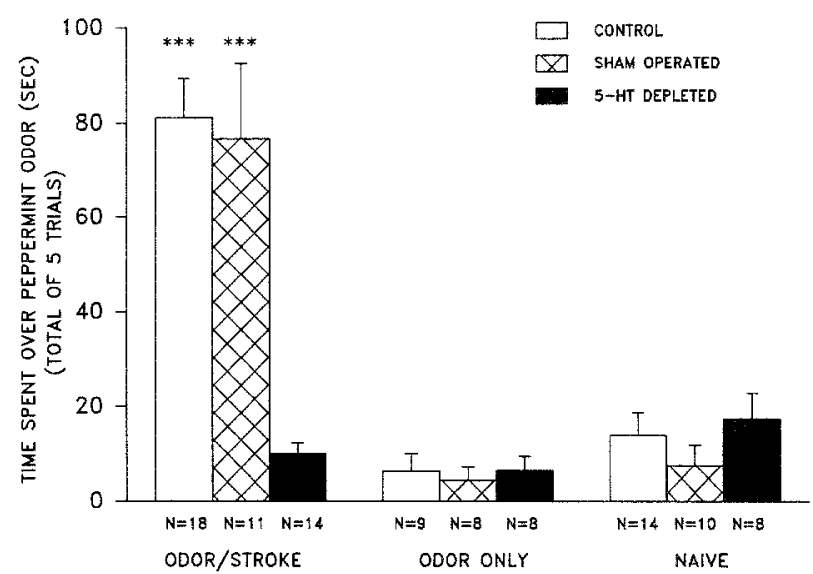

FIG. 1. Graph showing the time spent by PND 9 pups over peppermint odor 1 day after the pups were exposed to a 10-min odor/stroke, odor only, or naive paradigm. The pups were further divided into groups that included 5-HT depletion of the olfactory bulb, sham operated, and controls. The asterisks represent groups that spent significantly more time over the peppermint odor than the 5,7-dHT-injected pups.

permint odor the next day when presented with a choice between the peppermint odor and normal bedding (Fig. 1). ANOVA showed extremely significant differences among the means of the nine groups analyzed: $F(9,100)=19.72, p<.0001$. Post hoc Bonferroni showed that 5-HT-depleted pups that were trained by odor/stroke were significantly different from similarly trained controls or shams ( $p$ $<.001)$. There was no significant difference in the test between the control and sham pups indicating that the operation itself did not impair the ability to acquire the odor learning. Control and shamoperated pups that were trained by odor only or that were naive exhibited similar time over the peppermint odor as the trained 5-HT-depleted pups (Fig. 1) indicating that pups normally did not prefer the peppermint odor (over fresh bedding) unless trained using the odor/stroke paradigm. The 5-HTdepleted pups that were not trained (naive) showed a significant $(p<.001)$ preference for the normal (fresh) bedding odor using the Wilcoxon signed rank test. A significant preference of normal bedding over peppermint was also observed with nontrained control $(p<.0001)$ and sham-operated pups $(p<.005)$ indicating that the pups were able to differentiate the normal odor and peppermint odor and preferred the normal bedding (Fig. 2). The only groups that showed preference for the peppermint odor were odor/stroke control $(p<.0005)$ and sham-opperated pups $(p<.05)$.

One consideration in assessing whether the pups could smell normally was if the operated pups were 


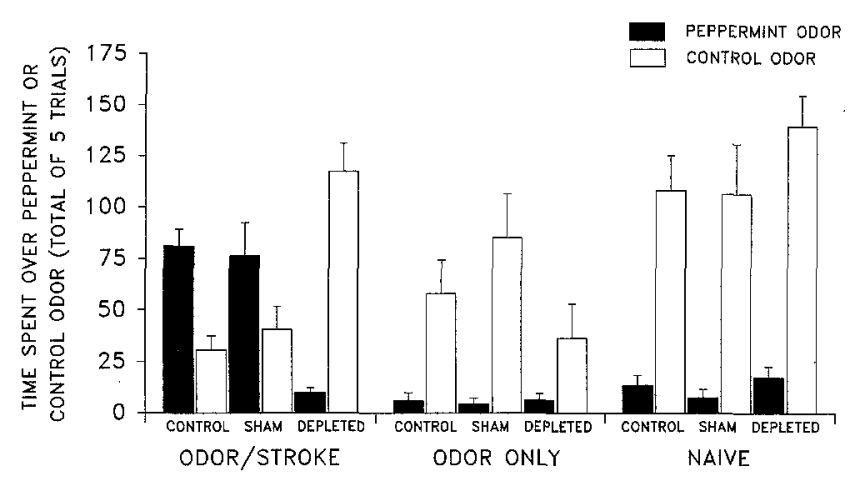

FIG. 2. Graph showing the same conditions as in Fig. 1 except that the time spent over the normal bedding odor is included. The Wilcoxon paired rank test showed significant differences $(p$ $<.05$ ) between the time spent over normal odor compared to peppermint odor within individual groups.

of normal weight since olfactory cues are required for nipple attachment (Pedersen et al., 1982). When all animals were considered, both male and female 5-HT-depleted pups tended to weigh less than the control and sham-operated pups (Table 1). Thus, the results indicate that the 5,7-dHT surgeries tended to decrease the weights of pups while surgery alone did not significantly affect weight.

The variation in litter size affected pup size to some extent; pups in larger litters (14-17 pups) tended to be smaller than pups in smaller litters (8-10 or 11-12) as shown in Table 1 . The primary focus of this study was not to examine the effect of litter size on learning. However, when the time spent over peppermint odor was examined in control odor/stroke pups of small litters $(95 \pm 14 \mathrm{~s}, n=$ 7 ), medium-sized litters ( $77 \pm 13 \mathrm{~s}, n=7$ ), or large litters $(64 \pm 9 \mathrm{~s}, n=4)$, there was an interesting nonsignificant (ANOVA comparisons between the three groups) trend for smaller litters to spend more time over the peppermint odor than larger litters. This trend did not affect the primary findings of the study, i.e., that 5-HT depletions affect the ability of pups to prefer the peppermint odor.

\section{Locomotor Test}

In the present experiments, it was found that pups with 5,7-dHT injections into AON displayed little time spent over the peppermint odor. Other studies have shown that extensive depletion of serotonergic pathways causes changes in the locomotory behavior of rats (Motles et al., 1991; Vanderwolf, 1989). Thus, it was imperative to determine if the lack of time spent over the peppermint odor was due to a lack of locomotor abilities. Locomotor testing of pups on PND 10 or PND 13/14 showed no significant difference between controls, sham-operated, and 5HT-depleted animals when subjected to ANOVA statistics. For example, the number of squares (mean \pm standard error of the mean) entered by the pups during a 3 -min open field test was 22.6 $\pm 4.9(N=19$ controls $), 22.1 \pm 3.0(N=15$ shams $)$, and $19.8 \pm 2.1(N=18,5,7-\mathrm{dHT}$-injected pups). These results indicated that the significantly less time spent over the peppermint by 5,7-dHT-injected pups was not due to problems of locomotion.

TABLE 1

Body Weights (grams) of PND 8 Pups after Different Treatments

\begin{tabular}{|c|c|c|c|c|c|c|}
\hline \multirow[b]{2}{*}{ Litter size } & \multicolumn{3}{|c|}{ Male } & \multicolumn{3}{|c|}{ Female } \\
\hline & Control & $\begin{array}{l}\text { Sham- } \\
\text { operated }\end{array}$ & $\begin{array}{c}\text { 5-HT } \\
\text { depleted }\end{array}$ & Control & $\begin{array}{l}\text { Sham- } \\
\text { operated }\end{array}$ & $\begin{array}{c}5 \text {-HT } \\
\text { depleted }\end{array}$ \\
\hline $8-10$ & $20.1 \pm 1.5^{a}$ & $18.4 \underset{(4)}{ \pm} 0.8^{b}$ & $\begin{array}{r}16.0 \\
(1)\end{array}$ & $\begin{array}{c}16.2 \pm 3.3 \\
(3)\end{array}$ & $17.6 \underset{(5)}{ \pm} 0.8^{c}$ & $13.7 \underset{(2)}{ \pm} 1.1$ \\
\hline $11-12$ & $\begin{array}{c}15.4 \pm 0.2 \\
(11)\end{array}$ & $12.9 \pm 1.0$ & $\begin{array}{c}12.8 \pm 0.6 \\
(8)\end{array}$ & $\begin{array}{c}14.9 \pm 0.3 \\
(7)\end{array}$ & $13.1 \pm 0.4$ & $11.8 \pm 0.5$ \\
\hline $14-17$ & $\begin{array}{c}13.6 \pm 0.6 \\
(7)\end{array}$ & $12.0 \pm 0.4$ & $\begin{array}{c}12.7 \pm 0.8 \\
(4)\end{array}$ & $13.1 \underset{(4)}{ \pm} 0.7$ & $\begin{array}{c}12.2 \pm 0.8 \\
(5)\end{array}$ & $\begin{array}{c}10.8 \pm 0.9 \\
(6)\end{array}$ \\
\hline All pups & $\begin{array}{c}15.7 \pm 0.6 \\
(21)\end{array}$ & $\begin{array}{c}14.1 \pm 0.4^{d} \\
(14)\end{array}$ & $\begin{array}{c}13.0 \pm 0.4^{d} \\
(13)\end{array}$ & $\begin{array}{c}14.1 \pm 0.4 \\
(14)\end{array}$ & $\begin{array}{c}14.3 \pm 0.7 \\
(15)\end{array}$ & $\begin{array}{c}11.7 \pm 0.5^{\circ} \\
(16)\end{array}$ \\
\hline
\end{tabular}

Note. Values are means \pm SEM the number of animals are in parentheses. All statistical tests utilized ANOVA analysis followed by post hoc Bonferroni $t$ tests.

${ }^{a}$ Significantly different $(p<.001)$ from control pups of larger litters $(11-12,14-17)$.

${ }^{b}$ Significantly different $(p<.01)$ from sham-operated pups of larger litters $(11-12,14-17)$.

- Significantly different $(p<.05)$ from sham-operated pups of larger litters (14-17).

${ }^{a}$ Significantly different $(p<.05)$ from male control pups when all pups, regardless of litter size, were considered.

- Significantly different $(p<.05)$ from female control and sham operated pups when all pups were considered. 

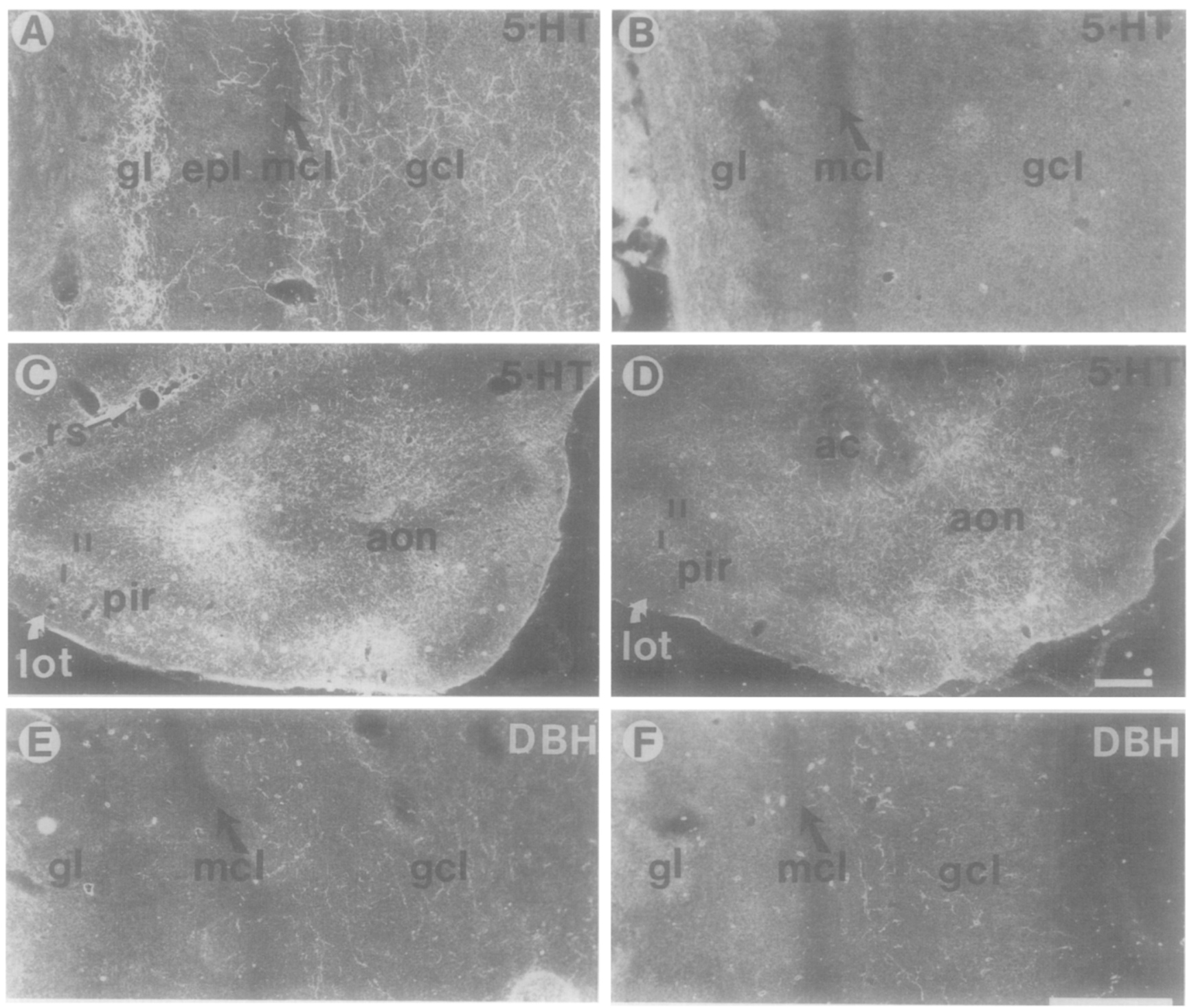

FIG. 3. Darkfield photomicrographs of immunocytochemically stained olfactory bulbs $(A, B, E, F)$ and anterior piriform cortex (C,D) in controls (photomicrographs on the left) and 5-HT-depleted pups (photomicrographs on the right). The sections were stained with antibodies to serotonin (5-HT) and dopamine- $\beta$-hydroxylase (DBH). Bars in D and F are $100 \mu \mathrm{m}$. A,B,E, and F are the same magnification. $\mathrm{C}$ and $\mathrm{D}$ are the same magnification. Abbreviations used: aon, anterior olfactory nucleus; ac, anterior commissure; epl, external plexiform layer; gcl, granule cell layer; gl, glomerular layer; lot, lateral olfactory tract; mcl, mitral cell layer; pir, piriform cortex with layers I and II.

\section{Verification of the Specificity of 5-HT Depletions}

Immunocytochemical analysis of the olfactory bulb and more caudal regions was performed to determine if 5-HT depletion was limited to the olfactory bulb and to ensure that other neurotransmitter systems in the olfactory bulb such as noradrenergic axons (originating from the locus coeruleus (Shipley, Halloran, \& de la Torre, 1985; McLean et al., 1989)) and intrinsic dopaminergic periglomerular cells were not affected by the 5-HT depletion. To accomplish this verification, depleted, sham-operated, and control animals were perfused and brain sections were analyzed quantitatively for the degree of immunocytochemical staining of serotonergic and noradrenergic (dopamine- $\beta$-hydroxylase) fibers in the olfactory bulb and piriform cortex and the dopaminergic (tyrosine hydroxylase immunocytochemistry) neurons in the bulb.

5-HT depletion. In the brains of 5-HT-depleted pups, there was virtually no 5-HT remaining in the glomeruli of the main olfactory bulb compared to controls (Figs. 3A and 3B) and very little remained in the deeper layers of the bulb (Table 2). In layer I of the anterior piriform cortex the serotonergic 
TABLE 2

Density $\left(\mu \mathrm{m} / 100 \mu \mathrm{m}^{2}\right)$ of 5-HT and Dopamine- $\beta$-hydroxylase (DBH)-Immunoreactive Fibers in the Olfactory Bulb (Glomerular Layer, GL; External Plexiform Layer, EPL; Inframitral Region) and Anterior Piriform Cortex (Layer I) of Control, Sham-Operated, and 5,7-dHT-Injected Pups

\begin{tabular}{lcccc}
\hline & GL & EPL & Inframitral & Piriform \\
\hline 5-HT & & & & \\
Control & $4.76 \pm 0.74$ & $1.64 \pm 0.50$ & $2.07 \pm 0.43$ & $3.91 \pm 0.65$ \\
& $(N=6)$ & $(N=6)$ & $(N=6)$ & $(N=5)$ \\
Sham & $4.15 \pm 0.37$ & $1.45 \pm 0.54$ & $2.10 \pm 0.34$ & $3.41 \pm 0.59$ \\
& $(N=6)$ & $(N=5)$ & $(N=5)$ & $(N=5)$ \\
5,7 -dHT & $0.19 \pm 0.16^{*}$ & $0.20 \pm 0.12$ & $0.34 \pm 0.12^{*}$ & $3.03 \pm 0.59$ \\
& $(N=6)$ & $(N=6)$ & $(N=6)$ & $(N=7)$ \\
DBH & & & & \\
Control & & $1.53 \pm 0.27$ & $1.54 \pm 0.17$ & $1.82 \pm 0.22$ \\
& & $(N=5)$ & $(N=5)$ & $(N=4)$ \\
Sham & & $1.12 \pm 0.32$ & $1.63 \pm 0.22$ & $2.33 \pm 0.15$ \\
& & $(N=4)$ & $(N=4)$ & $(N=5)$ \\
5,7-dHT & & $1.65 \pm 0.19$ & $2.01 \pm 0.17$ & $2.28 \pm 0.34$ \\
& & $(N=7)$ & $(N=7)$ & $(N=4)$ \\
\hline
\end{tabular}

Note. Densities are means $\pm \mathrm{SEM}$.

*Significantly different from sham and control pups at $p \leqslant$ .05 using ANOVA and the post hoc Bonferroni $t$ test. ANOVA for the glomerular layer: $F(3,17)=25.60, p<.0001$; ANOVA for the inframitral region: $F(3,17)=10.03, p<.05$.

innervation in 5-HT-depleted pups was not significantly different from sham-operated controls or nonoperated controls (Figs. 3C and 3D). In some animals, the serotonergic innervation of the cortex dorsal to the anterior olfactory nucleus (site of 5,7$\mathrm{dHT}$ injection) was depleted (due to spread of 5,7$\mathrm{dHT}$ along the needle tract) but the serotonergic innervation of other cortical regions appeared qualitatively normal. These results suggest that the serotonergic depletion to the olfactory bulb was effective and confined to the olfactory bulb and rostral anterior olfactory nucleus.

Effect of 5,7-dHT on norepinephrine and tyrosine hydroxylase. Since an intact noradrenergic system has previously been shown to be necessary for the acquisition of conditioned olfactory learning (Sullivan et al., 1989, 1991), it was important in the present study to determine if the 5,7-dHT depletions affected the noradrenergic system. Immunocytochemical analysis revealed that the noradrenergic fiber distribution (Figs. 3E and 3F) was normal. Analysis of the noradrenergic fiber density in the olfactory bulb and piriform cortex in 5-HT-depleted pups revealed no significant differences compared to controls and shams (Table 2). In addition, the dopaminergic periglomerular cells were distributed normally in the 5-HT-depleted animals. These observations demonstrated that pretreatment of the pups with desipramine was effective in blocking any potential adverse 5,7-dHT effects on the noradrenergic axons or dopaminergic neurons in the bulb and is in keeping with previous observations (Jonsson, 1980).

\section{DISCUSSION}

The present results are the first to suggest that normal serotonergic innervation of the olfactory bulb is necessary for conditioned olfactory learning. This innervation may be important for acquisition or expression (or both) of the olfactory-based learned behavior. Future studies are required to differentiate between the acquisition and the expression of the conditioned olfactory learning. However, the finding that serotonin is involved in conditioned olfactory learning at all is important because it provides a role for 5-HT in olfaction. In the past, very little has been known about the functional role of 5-HT in the bulb even though the serotonergic innervation to that structure is dense (McLean \& Shipley, 1987b) and arrives at a time when many developmental processes are occurring (McLean \& Shipley, 1987a). Thus, one would expect 5-HT to have modulatory effects over olfactory information at the earliest levels of synaptic processing in the CNS and this study suggests that this is the case.

\section{Effect of Serotonin Depletions on Locomotion, Weight, and Olfaction}

Arguments could be made that serotonin depletions of the olfactory bulb or system may have changed the capacity of pups to move since widespread serotonin depletions (Vanderwolf, 1989) or receptor agonists (Green \& Backus, 1990, for review) affects locomotion. However, the present study determined that specific serotonin depletion of the olfactory bulb (or system) did not affect locomotion. This serves to indicate that the serotonin depletion in the present study was not widespread and that the animals were able to move to the peppermint odor if they desired to do so.

The effect of the depletions on the weight and olfactory behavior is slightly more complicated to interpret than potential effects on locomotion. The depleted pups were generally smaller than controls and shams indicating that something more than just surgery caused the animals to lose weight. The depleted animals were, however, capable of suckling since they all survived the depletions and were able 
to feed. Other evidence that the pups could smell included their preference for normal bedding during the odor testing; had they been anosmic, they would have gone randomly over the normal bedding and peppermint bedding with a result of more or less equal time spent over each odor. One interpretation of the effect of serotonin depletion is that, without the serotonergic input to the bulb, the pup was lacking some ability to process olfactants properly (possibly due to disruption of conditioned olfactory learning). In such a scenario the olfactants (mother's milk) coupled with stroking may not have been as pleasurable to the depleted pup, so it did not feed as much. Various factors could have been involved in the weight loss. As an example, it may be the 5-HT depleted pups did not suckle as long or as often as control or sham-operated pups. Future experiments could be devised to explore further the reason why the depleted pups tended to be smaller.

It is interesting, but perhaps not surprising, that pups in larger litters tended to be somewhat smaller than pups in smaller litters. However, it is fascinating to note that smaller litters tended to show a greater preference for the conditioned odor than larger litters. This trend did not affect the primary findings of the study, i.e., that 5-HT depletions affect the ability of pups to prefer the peppermint odor. However, it would be interesting in future studies to test the hypothesis that smaller litters might be correlated with healthier, heavier pups and that these pups might learn better than pups from larger litters.

\section{Mechanisms of Serotonergic Action}

A prediction from the behavioral results of the present study would be that the presence of 5-HT is necessary for olfactory circuitry to facilitate or acquire the conditioned olfactory memories or their expression. One may speculate that the 5-HT enhances the circuitry or plasticity of circuitry to facilitate this learning although further studies would be needed to confirm this hypothesis. In the neocortex it appears that 5-HT may act to facilitate the excititory effects of the excitatory amino acid agonist N-methyl- $D$-aspartate (NMDA) on cortical neurons (Nedergaard, Engberg, \& Flatman, 1992; Reynolds, Baskys, \& Carlen, 1992). NMDA receptors have been shown to be important in long-term potentiation which is one physiological means that certain types of memory may be formed. Thus, it is possible that the acquisition of memories observed in the present study may be acting in a similar fashion. In this respect, NMDA receptors have been reported in the external plexiform layer of the olfactory bulb of neonates (Lincoln, Coopersmith, Harris, Monaghan, Cotman, \& Leon, 1986) and a recent study has found that blockade of NMDA receptors in young rats blocks conditioned olfactory learning (Lincoln, Coopersmith, Harris, Cotman, \& Leon, 1988). Because 5-HT is found in all layers of the bulb, this transmitter could possibly be interacting with the NMDA receptor at the external plexiform layer to produce a long-lasting change (memory) in olfactory responses to a conditioned stimulus.

Serotonergic interactions with NMDA receptors are not the only possible means by which 5 -HT could produce the results of this study. For example, 5$\mathrm{HT}$ in combination with cholinergic inputs is important in neocortical learning (Vanderwolf, Leung, Baker, \& Stewart, 1989; Vanderwolf, Baker, \& Dickson, 1990). Both these neurotransmitters are present in the bulb, especially within glomeruli, and could interact with cells in the bulb in some as yet unknown way to produce a long-term facilitation of circuitry resulting in learning of odors.

Given the results of the present study, there is some question as to the relationship of serotonin and norepinephrine in conditioned olfactory learning. The noradrenergic input is heavy to the deeper parts of the bulb in the adult rat (McLean et al., 1989) and fibers are present, albeit sparse, in the deeper layers during the first postnatal week (McLean \& Shipley, 1991). In addition, the noradrenergic system is active during states of arousal (Foote et al., 1983) or vigilance (Aston-Jones, Ennis, Pieribone, Nickell, \& Shipley, 1986) so it might be expected that this system would be involved in olfactory learning. Indeed, indirect methods of injecting noradrenergic $\beta$-receptor agonists or antagonists (propanolol) into the pup during olfactory training (Sullivan et al., 1989) have confirmed that it is involved in conditioned olfactory learning. Despite the evidence that norepinephrine is important in olfactory learning, it appears from the present study that the serotonergic fibers from the dorsal and median raphe nuclei (McLean \& Shipley, 1987b) are also necessary for acquisition and/or expression of olfactory learning. Whether the serotonergic and noradrenergic systems function independently in this behavior is not known.

\section{Interpretation of Serotonergic Specificity}

Several questions may arise regarding the experimental paradigm which was aimed at specifically depleting the serotonergic input to the olfac- 
tory bulb. An obvious issue is whether the 5,7-dHT injections into the anterior olfactory nucleus adversely affected the noradrenergic axons leading to the olfactory bulb. The noradrenergic system has been shown to be necessary for the acquisition of olfactory learning in rat pups so it was imperative in the present study to protect this system. The protection was achieved by injecting desipramine, a monoamine reuptake blocker, before the injection of 5,7-dHT. This pretreatment method has been used successfully in the past to protect against depletion of the noradrenergic system (Jonsson, Pollare, Hallman, \& Sachs, 1978; Jonsson, 1980; Zhou \& Azmitia, 1984) and it was also effective in the present study. The noradrenergic axons were present in normal distribution and density in the olfactory bulb and piriform cortex of 5,7-dHT-injected animals compared to controls and sham-operated pups. However, it is noteworthy that the noradrenergic fibers were slightly denser (nonsignificant using ANOVA) in inframitral regions of the olfactory bulb compared to controls and shams. Such an increase could possibly have contributed to the lack of conditioned olfactory learning in 5,7-dHT-treated animals since, in a somewhat similar situation, a noradrenergic agonist (isoproterenol) inhibits olfactory learning when the odor is paired with stroking or enhances olfactory learning when paired with odor only (Sullivan et al., 1989). In the present study, the increased density of noradrenergic fibers could have had the same effect as isoproterenol. However, pups that were depleted and trained only to peppermint odor (no stroking) did not show an increased preference to the peppermint odor indicating that the slight increase in norepinephrine fibers did not produce the stimulatory effect for learning that isoproterenol is hypothesized to do (Sullivan et al., 1989).

The serotonergic depletion was confirmed in 5,7dHT-treated animals by immunocytochemical visualization of serotonergic fibers. In most pups, there was complete bilateral depletion of the serotonergic input to the glomeruli of the bulb and in many cases complete depletion of the remaining layers of the bulb as well. In other cases, there were extant serotonergic axons in the bulb most likely due to either sparing of 5-HT axons or sprouting of remaining fibers in the anterior olfactory nucleus. No significant change in the serotonergic patterns or density of axons was observed caudal to the injection site in the rostral anterior olfactory nucleus. In fact, even the rostral anterior olfactory nucleus had normal 5-HT innervation in several animals although there was severe depletion of the 5-HT innervation of the main olfactory bulb. Qualitative visualization of other caudal regions indicated that serotonin was normal. Thus, overall the serotonergic input to the bulb was effectively and specifically depleted in the olfactory bulb (and lesser extent in the anterior olfactory nucleus) without adverse effect on the noradrenergic or dopaminergic systems as observed by immunocytochemistry. In addition to our immunocytochemical evidence that the manipulations did not adversely affect the density of noradrenergic fibers, another study showed that injecting desipramine followed by 5,7-dHT depletions in pups did not affect the functional status of cortical noradrenergic or dopaminergic systems (Ponzio \& Johnson, 1978). It is also possible that receptor levels for certain transmitter systems could be changed but receptors were not observed in this study. In addition, only selective neurotransmitters were examined in this study, i.e., glutamatergic, GABAergic, cholinergic, and other systems were not examined. However, judging from the available literature (Jonsson et al., 1978; Jonsson, 1980; Zhou \& Azmitia, 1984) and our own evaluation of 5,7dHT in the olfactory system, the toxic effects were quite selective to the serotonergic system. The fact that such a selective and extensive depletion to the olfactory bulb was accomplished with very little involvement of more caudal structures (anterior olfactory nucleus, piriform cortex) provides direct evidence that the serotonergic input to anterior olfactory structures is involved in the behavioral responses observed in this study.

A less specific means of blocking the actions of 5-HT would be to inject 5-HT receptor agonists or antagonists into the pups at the time of olfactory training. However, with such a paradigm it would be difficult, if not impossible, to determine the precise site of action of the drugs on the serotonergic system. In addition, and of potential importance, serotonergic antagonists or agonists have been shown to affect the noradrenergic locus coeruleus (Broderick \& Piercey, 1991; Bobker \& Williams, 1989; Simson \& Weiss, 1989) which, when activated enhances arousal (Foote et al., 1983) and olfactory learning (Wilson \& Leon, 1986, 1988). Therefore, injection of 5-HT receptor agonists or antagonists would not provide as interpretable results as provided by the specific depletions of 5-HT in the present study. Nevertheless, it would be of some benefit to supplement the 5-HT-depleted pups with 5-HT, if possible, to determine if the conditioned olfactory learning could be restored.

In summary, this study represents the initial suggestions that serotonin is involved in the acquisition 
and/or retrieval of conditioned olfactory learning. Given the paucity of information regarding the functional role of serotonin in the olfactory bulb, these results provide an important direction for further investigation.

\section{REFERENGES}

Aston-Jones, G., Ennis, M., Pieribone, V. A., Nickell, W. T., \& Shipley, M. T. (1986). The brain nucleus locus coeruleus: Restricted afferent control of a broad efferent network. Science, 234, 734-737.

Bobker, D. H., \& Williams, J. T. (1989). Serotonin agonists inhibit synaptic potentials in the rat locus ceruleus in vitro via 5-hydroxytryptamine $e_{1 \mathrm{~A}}$ and 5-hydroxytryptamine ${ }_{1 \mathrm{~B}}$ receptors. Journal of Pharmacology and Experimental Therapy, 250, 37-43.

Broderick, P. A., \& Piercey, M. F. (1991), 5-HT ${ }_{1 \mathrm{~A}}$ agonists uncouple noradrenergic somatodendritic impulse flow and terminal release. Brain Research Bulletin, 27, 693-696.

Burrows, G. D., McIntyre, I. M., Judd, F. K., \& Norman, T. R. (1988). Clinical effects of serotonin reuptake inhibitors in the treatment of depressive illness. Journal of Clinical Psychiatry, 49 (Suppl.) 18-22.

Corbett, D., Evans, S., Thomas, C., Wang, D., \& Jonas, R. A. (1990). MK-801 reduced cerebral ischemic injury by inducing hypothermia. Brain Research, 514, 300-304.

Curzon, G. (1988). Serotonergic mechanisms of depression. Clinical Neuropharmacology, 11(Suppl. 2), S11-S20.

Foote, S. L., Bloom, F. E., \& Aston-Jones, G. (1983). Nucleus locus ceruleus: New evidence of anatomical and physiological specificity. Physiological Reviews, 63, 844-914.

Green, A. R. \& Backus, L. I. (1990). Animal models of serotonin behavior. Annals of the New York Academy of Sciences, 600, 237-249.

Johanson, I. B., \& Hall, W. G. (1982). Appetitive conditioning in neonatal rats: Conditioned orientation to a novel odor. Developmental Psychobiology, 15, 379-397.

Jonsson, G. (1980). Chemical neurotoxins as denervation tools in neurobiology. Annual Review of Neuroscience, 3, 169187.

Jonsson, G., Pollare, T., Hallman, H., \& Sachs, Ch. (1978). Developmental plasticity of central serotonin neurons after 5,7 dihydroxytryptamine treatment. Annals of the New York Academy of Sciences, 305, 328-344.

Kosofsky, B. E., \& Molliver, M. E. (1987). The serotoninergic innervation of cerebral cortex. Synapse, 1, 153-168.

Lauder, J. M. (1990). Ontogeny of the serotonergic system in the rat: Serotonin as a developmental signal. Annals of the New York Academy of Sciences, 600, 297-314.

Lauder, J. M., Wallace, J. A., Krebs, H., Petrusz, P., \& McCarthy, $K$. (1982). In vivo and in vitro development of serotonergic neurons. Brain Research Bulletin, 9, 605-625.

Lidov, H. G. W., Grzanna, R., \& Molliver, M. E. (1980). The serotonin innervation of the cerebral cortex in the rat-an immunohistochemical analysis. Neuroscience, 5, 207-227.

Lincoln, J., Coopersmith, R., Harris, E. W., Cotman, C. W., \& Leon, M. (1988). NMDA receptor activation and early olfactory learning. Developmental Brain Research, 39, 309312.
Lincoln, J., Coopersmith, R., Harris, E. W., Monaghan, D. T., Cotman, C. W., \& Leon, M. (1986). NMDA receptor blockade prevents the neural and behavioral consequences of early olfactory learning. Society for Neuroscience Abstracts, 12, 124.

Maeda, T., Fujimiya, M., Kitahama, K., Imai, H., \& Kimura, H. (1989). Serotonin neurons and their physiological roles. Archives of Histology and Cytology, 52(Suppl.) 113-120.

Mason, R. (1988). Altered neuronal sensitivity of lateral geniculate neurones to noradrenaline and 5 -HT following exposure to continuous lighting. Neurosciences Letters 92, 102107.

McLean, J. H. (1991). Does serotonergic input influence development of a cortical structure? IBRO World Congress of Neuroscience, 3, 42 [Abstract]

McLean, J. H., \& Shipley, M. T. (1987a). Serotonergic afferents to the rat olfactory bulb. II. Changes in fiber distribution during development. Journal of Neuroscience, 7, 3029-3039.

McLean, J. H., \& Shipley, M. T. (1987b). Serotonergic afferents to the rat olfactory bulb. I. Origins and laminar specificity of serotonergic inputs in the adult rat. Journal of Neuroscience, 7, 3016-3028.

McLean, J. H., \& Shipley, M. T. (1988). Postmitotic, postmigrational expression of tyrosine hydroxylase in olfactory bulb dopaminergic neurons. Journal of Neuroscience, 8, 36583669.

McLean, J. H., \& Shipley, M. T. (1991). Postnatal development of the noradrenergic projection from locus coeruleus to the olfactory bulb in the rat. Journal of Comparative Neurology, 304, 467-477.

McLean, J. H., Shipley, M. T., Nickell, W. T., Aston-Jones, G., \& Reyher, C. K. (1989). Chemoanatomical organization of the noradrenergic input from locus coeruleus to the olfactory bulb of the adult rat. Journal of Comparative Neurology, 285, 339-349.

Motles, E., Gomez, A., Briones, C., \& Gonzalez, M. (1991). Effects of $p$-chloro-phenylalanine on the behaviors induced by apomorphine and amphetamine in adult cats. Progress in Neuropsychopharmacology \& Biological Psychiatry, 15, 105-117.

Nedergaard, S., Engberg, I., \& Flatman, J. A. (1992). The modulation of excitatory amino acid responses by serotonin in the cat neocortex in vitrol. Cellular and Molecular Neurobiology, 7, 367-379.

Normile, H. J., Jenden, D. J., Kuhn, D. M., Wolf, W. A., \& Altman, H. J. (1990), Effects of combined serotonin depletion and lesions of the nucleus basalis magnocellularis on acquisition of a complex spatial discrimination task in the rat. Brain Research, 536, 245-250.

Pedersen, P. E., Williams, C. L., \& Blass, E. M. (1982). Activation and odor conditioning of suckling behavior in 3-day old albino rats. Journal of Experimental Psychology: Animal Behavior Processes, 8(4), 329-341.

Ponzio, F., \& Jonsson, G. (1978). Effects of neonatal 5,7-dihydroxytryptamine treatment on the development of serotonin neurons and their transmitter metabolism. Developmental Neuroscience, 1, 80-89.

Reynolds, J. N., Baskys, A., \& Carlen, P. L. (1992). The effects of serotonin on $N$-methyl-D-aspartate and synaptically evoked depolarizations in rat neocortical neurons. Brain Research, 456, 286-292.

Sakurai, Y., \& Wenk, G. L. (1990). The interaction of acetyl- 
cholinergic and serotonergic neural systems on performance in a continuous non-matching to sample task. Brain Research, 519, 118-121.

Shipley, M. T., Halloran, F. J., \& de la Torre, J. (1985). Surprisingly rich projection from locus coeruleus to the olfactory bulb in the rat. Brain Research, 329, 294-299.

Simson, P. E., \& Weiss, J. M. (1989). Blockade of $\alpha_{2}$-adrenergic receptors, but not blockade of $\delta$-aminobutyric acid $_{\mathrm{A}}$, serotonin, or opiate receptors, augments responsiveness of locus coeruleus neurons to excitatory stimulation. Neuropharmacology, 28, 651-660.

Sullivan, R. M., \& Hall, W. G. (1988). Reinforcers in infancy: Classical conditioning using stroking or intra-oral infusions of milk as UCS. Developmental Psychobiology, 21, 215-223.

Sullivan, R. M., Hofer, M. A., \& Brake, S. C. (1986). Olfactoryguided orientation in neonatal rats is enhanced by a conditioned change in behavioral state. Developmental Psychobiology, 19, 615-623.

Sullivan, R. M., \& Leon, M. (1986). Early olfactory learning induces an enhanced olfactory bulb response in young rats. Developmental Brain Research, 27, 278-282.

Sullivan, R. M., McGaugh, J. L., \& Leon, M. (1991). Norepinephrine-induced plasticity and one-trial olfactory learning in neonatal rats. Developmental Brain Research, 60, 219228.

Sullivan, R. M., \& Wilson, D. A. (1991). The role of norepinephrine in the expression of learned olfactory neurobehavioral responses in infant rats. Psychobiology, 19, 308312 .

Sullivan, R. M., Wilson, D. A., \& Leon, M. (1989). Norepinephrine and learning-induced plasticity in infant rat olfactory system. Journal of Neuroscience, 9, 3998-4006.
Syvalahti, E. (1987). Monoaminergic mechanisms in affective disorders. Medical Biology, 65, 89-96.

Vanderwolf, C. H. (1989). A general role for serotonin in the control of behavior: Studies with intracerebral 5,7-dihydroxytryptamine. Brain Research, 504, 192-198.

Vanderwolf, C. H. (1992). The electrocorticogram in relation to physiology and behavior: A new analysis. Electroencephalography and Clinical Neurophysiology, 82, 165-175.

Vanderwolf, C. H., Baker, G. B., \& Dickson, C. (1990). Serotonergic control of cerebral activity and behavior: Models of dementia. Annals of the New York Academy of Sciences, 600, 366-383.

Vanderwolf, C. H., Leung, L. W. S., Baker, G. B., \& Stewart, D. J. (1989). The role of serotonin in the control of cerebral activity-Studies with intracerebral 5,7-dihydroxytryptamine. Brain Research, 504, 181-191.

Waterhouse, B. D., Moises, H. C., \& Woodward, D. J. (1986). Interaction of serotonin with somatosensory cortical neuronal responses to afferent synaptic inputs and putative neurotransmitters. Brain Research Bulletin, 17, 507-518.

Weldon, D. A., Travis, M. L., \& Kennedy, D. A. (1991). Posttraining D1 receptor blockade impairs odor conditioning in neonatal rats. Behavioral Neuroscience, 105, 450-458.

Wilson, D. A., \& Leon, M. (1986). Early appearance of inhibition in the neonatal rat olfactory bulb. Developmental Brain Research, 26, 289-292.

Wilson, D. A., \& Leon, M. (1988). Noradrenergic modulation of olfactory bulb excitability in the postnatal rat. Brain Research, 470, 69-75.

Zhou, F., \& Azmitia, E. C. (1984). Induced homotypic collateral sprouting of serotonergic fibers in the hippocampus of rat. Brain Research, 308, 53-62. 